\title{
EXTERNAL QUANTUM EFFICIENCY AND FIRST RESULTS OF ELECTRIC PERFORMANCE MEASUREMENTS ON A QUADRUPLE JUNCTION SPACE SOLAR CELL
}

\author{
Grás, A. ${ }^{(1)}$, Jüngst, G. ${ }^{(2)}$, Campesato, R. ${ }^{(3)}$, Gori, G. ${ }^{(3)}$, Greco, E. ${ }^{(3)}$ \\ (1) INTA-SPASOLAB, Carretera de Ajalvir km. 4, 28850 Torrejón de Ardoz (Spain), Email: grassa@inta.es \\ (2) ISDEFE Consulting, C/ Beatriz de Bobadilla 3, 28040 Madrid (Spain),Email: jungstg.pers externo@inta.es \\ (3) CESI S.p.A., Via Rubattino 134, 20134 Milano (Italy), Email: roberta.campesato@,cesi.it
}

\begin{abstract}
External Quantum Efficiency (EQE) and CurrentVoltage (I-V) measurements of a monolithic quadruple junction (4J) space solar cell AlGaInP (J1)/ AlInGaAs (J2) / InGaAs (J3) / Ge (J4) manufactured by CESI (Milano, Italy) have been performed at INTA-Spasolab. In order to determine electrical cell performance of this 4J solar cell type under AM0 irradiance and cell temperature standard conditions, the external quantum efficiency (EQE) measurement system and steady-state solar simulators at the cell testing laboratory INTASpasolab are to be upgraded. The purpose of this work is to present both the upgrading of INTA-Spasolab facilities and the results of the characterization of a $4 \mathrm{~J}$ solar cell under development.
\end{abstract}

\section{INTRODUCTION}

Electrical performance characterization of new coming space multi-junction solar cells have required solar simulators to evolve from basic, single source systems to multi-source systems capable of providing test illumination conditions much closer to the reference AM0 spectrum. For accurate I-V measurements of monolithic multi-junction (MJ) solar cells, the spectrum of the solar simulator has to be adjusted such that each sub-cell of the MJ cell generates the same photocurrent as under the reference spectrum. The procedures to adjust the multi-source systems [1-4] usually involve the calculation of the so-called spectral mismatch factor for each junction for which EQE measurement of the sub-cells are necessary.

Manufacturers of space solar cells are working on increasing the number of junctions of III-V semiconductor based solar cells by a combination of semiconductors with different band-gaps to further improve the already high efficiencies of $\mathrm{InGaP} / \mathrm{InGaAs} / \mathrm{Ge}$ triple junction solar cells (above 30\% in AM0 conditions) widely used in space applications due to their radiation resistance. Solar simulators are to be conditioning by adding and/or adapting spectrally their light sources in order to provide an accurate AM0 spectral match according to specific devices.
CESI is investigating the design of a monolithic quadruple junction (4J) space solar cell AlGaInP/ AlInGaAs/ (In)GaAs/ Ge that can be grown entirely by MOCVD toward the optimization of a $32 \% 4 \mathrm{~J}$ lattice matched solar cell solution for space applications [5]. The approach to optimise the final four junction device is an iterative one: the solar cell structure is designed and simulated by the code, and then the solar cells are manufactured and tested. The experimental results from characterisation provide the feedback needed to improve the input parameters to the code and then to restart optimisation. The InGaAs junction was found to be the limiting sub-cell in the first four junction devices samples that have been manufactured and tested. This sub-cell determined a low radiation resistance in such devices. A 4J solar cell with modification of the former InGaAs structure [6] has been characterized at INTASpasolab.

\section{TEST EQUIPMENT}

\subsection{EQE Measurement System}

The EQE measurement system of INTA-Spasolab as well as the electrical characterisation method of multijunction solar cells is described elsewhere in $[2,7]$. As depicted in Fig. 1, bias light illumination can be easily adapted by optical bandpass filter change, so that measurements can be switched quickly from three junctions to four junctions III-V cells.

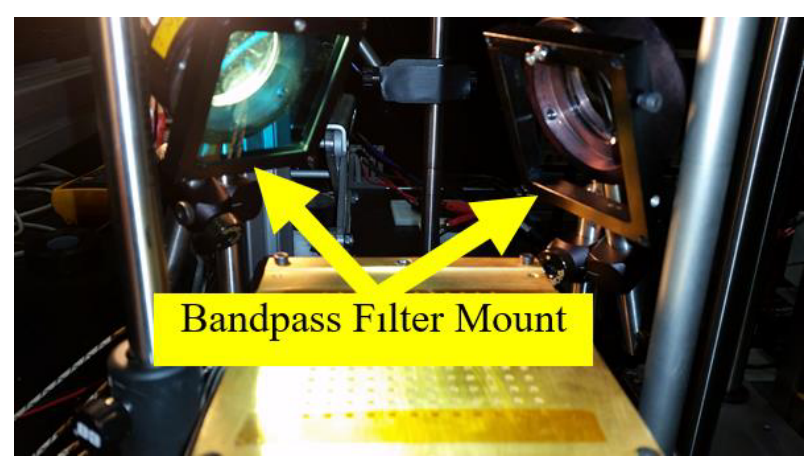

Figure 1. Optical Bandpass Filter Mount. 
Long (LP) and short (SP) bandpass filters used on bias light sources for EQE measurements on $4 \mathrm{~J}$ sub-cells are listed in Tab. 1.

Table 1. Bandpass filters for EQE $4 J$ cell measurements

\begin{tabular}{cc}
\hline Sub-cell & Bandpass Filter \\
\hline $\mathrm{J} 1$ & LP700 nm \\
$\mathrm{J} 2$ & $\mathrm{SP} 540 \mathrm{~nm}+\mathrm{LP} 830 \mathrm{~nm}$ \\
$\mathrm{~J} 3$ & SP600 nm \\
$\mathrm{J} 4$ & Coldglass KG5 \\
\hline
\end{tabular}

\subsection{J Solar Simulator}

A commercial steady-state solar simulator based on a short-arc xenon lamp (Xe) with a light set up so far used for measurements of state-of-art triple junction solar cells (3J) $\mathrm{GaInP} / \mathrm{InGaAs} / \mathrm{Ge}$ has been upgraded. As depicted in Fig. 2, spectrally filtered halogen light sources can be placed and combined on an external ring as required to meet finally effective irradiance unity at each sub-cell of the $4 \mathrm{~J}$ cell. In total, three sets of assembled halogen light sources (Ha1, Ha2 and $\mathrm{Ha} 3$ ) have been utilised. The incident angle of this supplementary-light illumination is fixed within $30^{\circ}$ to maintain cosine signal response of solar cells.

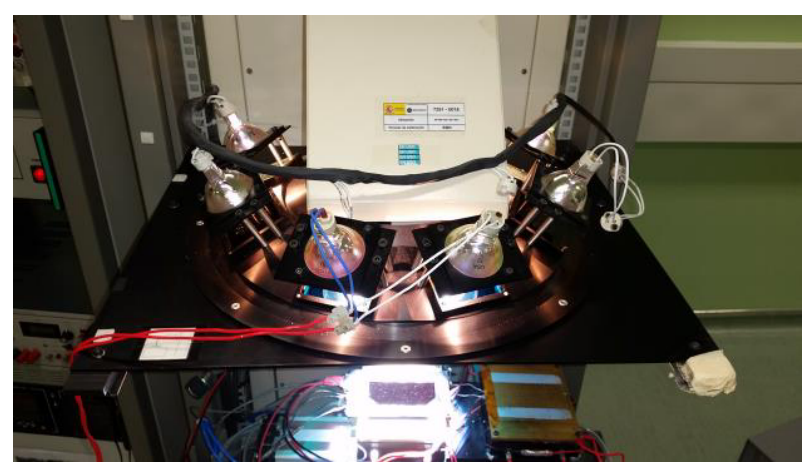

Figure 2. Additional halogen light sources for a single simulator solar simulator.

In order to achieve AM0 equivalent conditions of illumination with a four- light source simulator, a set of single-junction reference solar cells (SCRC) is used to adjust the irradiance level of each light source on the test plane in a way that the AM0 calibration value of each reference cell is achieved. The selected 4J SCRC set represent a spectral response range similar to the $4 \mathrm{~J}$ cell to be tested, which is shown in Fig. 3. This set is comprised by the following:

- CESI model CTJ-4J, 80x40 $\mathrm{mm}^{2}$ with $30.15 \mathrm{~cm}^{2}$ active area: AlInGaP/Ge (J1), AlInGaAs/Ge (J2) and $\mathrm{InGaAs} / \mathrm{Ge}(\mathrm{J} 3)$. All of them with active Germanium sub-cell.

- $\quad$ AZUR SPACE 3G28, 80x40mm²: Ge (J4)

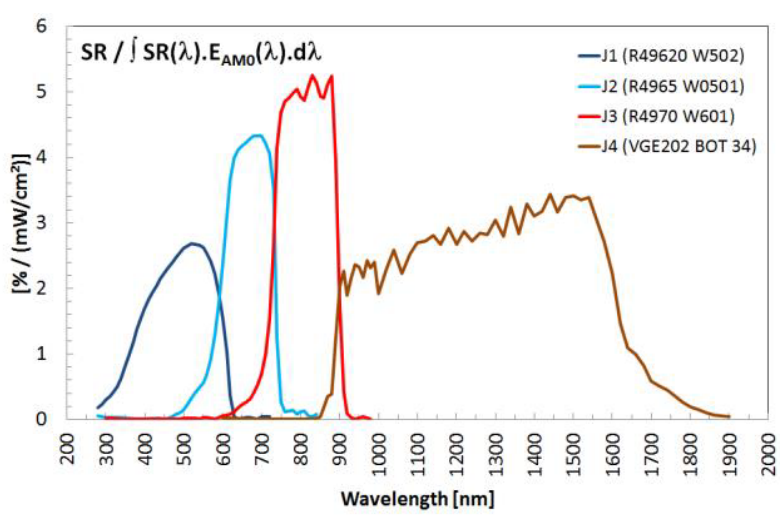

Figure 3. Spectral Response curves of the 4J single component reference cells (SCRC) set.

The spectral distribution curves of each light source of the $4 \mathrm{~J}$ solar simulator at AM0 conditions are depicted in Fig. 4.

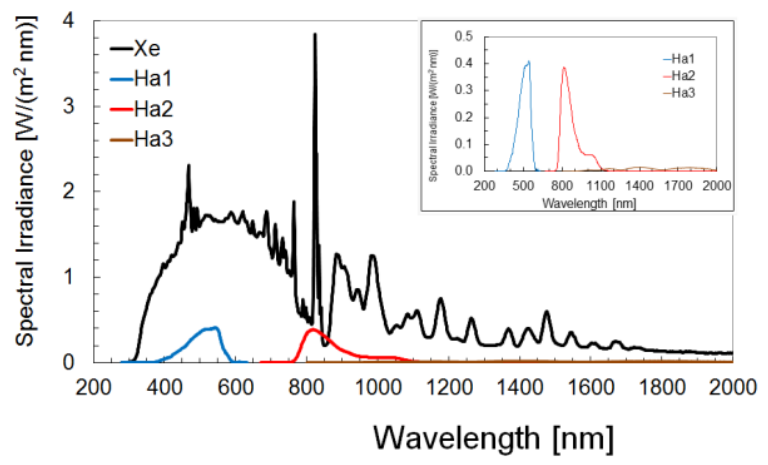

Figure 4. Spectral distribution of light source sets

The contribution of the different light sources of the $4 \mathrm{~J}$ solar simulator to the short circuit current of each SCRC at AM0 equivalent illumination is indicated in Tab. 2

Table 2. Contribution of each light source to the shortcircuit current of the SCRC at AMO equivalent illumination

\begin{tabular}{ccccc}
\hline $\begin{array}{c}\text { Light } \\
\text { Source }\end{array}$ & $\mathbf{J 1}$ & $\mathbf{J 2}$ & $\mathbf{J 3}$ & $\mathbf{J 4}$ \\
\hline $\mathrm{Xe}$ & $90 \%$ & $99 \%$ & $83 \%$ & $87 \%$ \\
$\mathrm{Ha} 1$ & $10 \%$ & $1 \%$ & $0 \%$ & $0 \%$ \\
$\mathrm{Ha} 2$ & $0 \%$ & $0 \%$ & $17 \%$ & $3 \%$ \\
$\mathrm{Ha} 3$ & $0 \%$ & $0 \%$ & $0 \%$ & $10 \%$ \\
\hline
\end{tabular}

The nonconformity in the spatial uniformity (UF) of irradiance in the working plane for each junction and corresponding relevant class of solar simulator according to [8] is in Tab. 3.

Table 3. Nonconformity of irradiance uniformity

\begin{tabular}{ccccc}
\hline 4J Solar Simulator & $\mathbf{J 1}$ & $\mathbf{J 2}$ & $\mathbf{J 3}$ & $\mathbf{J 4}$ \\
\hline UF Nonconformity & $\pm 5 \%$ & $\pm 2 \%$ & $\pm 6 \%$ & $\pm 3 \%$ \\
Class & $\mathrm{B}$ & $\mathrm{A}$ & $\mathrm{C}$ & $\mathrm{B}$ \\
\hline
\end{tabular}




\section{TEST RESULTS}

\subsection{External Quantum Efficiency}

EQE measurement results of the aforementioned 4J solar cell obtained using the EQE system previously described are presented in Fig. 5.

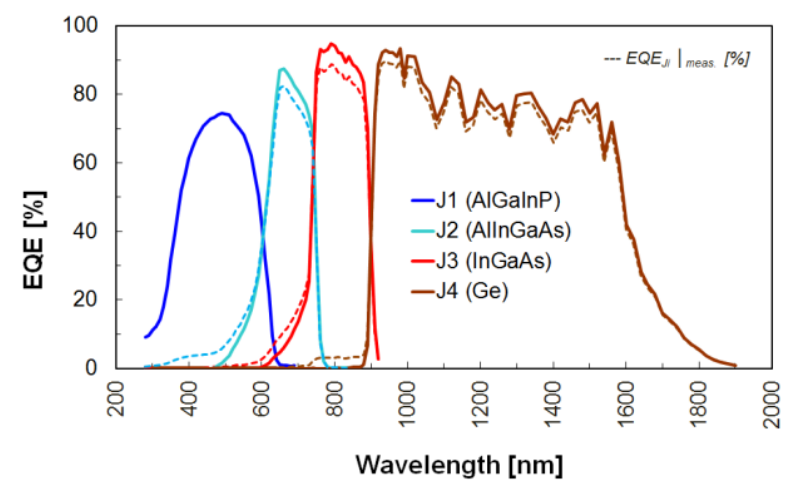

Figure 5. EQE results of the $4 J$ solar cell

Measured EQE curves for the higher bandgap junctions show artefacts in the spectral range of the lower bandgap junctions. The presence of non-desired parasitic EQE when performing EQE measurement of a sub-cell could be related either to low shunts resistance of the sub-cell under test [9] or to luminescence coupling [10]. EQE measured values are then to be corrected to remove such artefacts. Although the physics involved are different, the mathematical procedure in $[9,10]$ to correct such artefacts is similar. The measured EQE values of the higher band junctions have been then corrected to get the actual EQE values. The results in Tab. 4 show the contribution of actual $\mathrm{EQE}$ values to the measured $\mathrm{EQE}$ ones.

Table 4. Contribution of actual EQE values to the measured EQE for each sub-cell of the $4 \mathrm{~J}$ cell

\begin{tabular}{ccccc}
\hline EQE $\left._{\mathbf{J}}\right|_{\text {meas }}$ & EQE $_{\mathbf{J} 1}$ & EQEJ2 $_{\mathbf{J}}$ & EQE $_{\mathbf{J 3}}$ & EQE $_{\mathbf{J} 4}$ \\
\hline $\mathbf{J 1}$ & $\mathbf{1 0 0 \%}$ & - & - & - \\
$\mathbf{J 2}$ & $5.9 \%$ & $\mathbf{9 4 . 1 \%}$ & - & - \\
$\mathbf{J 3}$ & $0.6 \%$ & $10.4 \%$ & $\mathbf{8 9 . 0 \%}$ & - \\
$\mathbf{J 4}$ & $0.0 \%$ & $0.15 \%$ & $4.35 \%$ & $\mathbf{9 5 . 5 \%}$ \\
\hline
\end{tabular}

\subsection{Current-Voltage Curve}

The testing procedure to establish AM0 equivalent illumination conditions for multi-junction solar cells applied at INTA-Spasolab is described in [2,4]. This procedure requires the measurement of the relative spectral irradiance of each light source at different lamp intensities to compute the corresponding spectral mismatch correction factor for each junction using relative spectral measurements of both, SCRC and related junction of the $4 \mathrm{~J}$ cell, from the previously measured EQE in Fig. 3 and Fig. 4. The spectral mismatch parameter for each junction was found to be the same for the full operating range of each source.
The spectral mismatch factors to be applied when adjusting the $4 \mathrm{~J}$ solar simulator to AM0 equivalent illumination conditions for the $4 \mathrm{~J}$ solar cell are given in Tab. 5.

Table 5. Applied Spectral Mismatch Factors (M)

\begin{tabular}{|ccccc|}
\hline $\begin{array}{c}\text { Light } \\
\text { Source }\end{array}$ & J1 & J2 & J3 & J4 \\
\hline Xe & 1.005 & 0.999 & 1.000 & 1.026 \\
Ha1 & 0.970 & 0.782 & - & - \\
Ha2 & - & 0.183 & 1.003 & 0.932 \\
Ha3 & - & - & - & 1.004 \\
\hline
\end{tabular}

During the $4 \mathrm{~J}$ solar simulator setting process, the AM0 effective irradiance for each sub-cell junction is computed by using the measured short-circuit current values of the 4J SCRC set and applying the corresponding spectral mismatch factor. Effective irradiance results are given in Tab. 6, where the junction used to set the different light sources in bold is highlighted.

Table 6. AM0 effective irradiance for each sub-cell

\begin{tabular}{lcccc}
\hline $\begin{array}{c}\text { AM0 effective } \\
\text { irradiance }\end{array}$ & J1 & J2 & J3 & J4 \\
\hline $\mathbf{X e}$ & 0.903 & 0.993 & 0.829 & 0.880 \\
$\mathrm{Xe}+\mathrm{Ha} 1$ & 0.999 & 1.000 & 0.824 & 0.888 \\
$\mathrm{Xe}+\mathrm{Ha} 1+\mathrm{Ha} 2$ & 0.999 & 1.000 & 1.004 & 0.919 \\
$\mathrm{Xe}+\mathrm{Ha} 1+\mathrm{Ha} 2+\mathbf{H a 3}^{[1]}$ & $\mathbf{0 . 9 9 9}$ & $\mathbf{1 . 0 0 0}$ & $\mathbf{1 . 0 0 4}$ & $\mathbf{1 . 0 2 0}$ \\
\hline
\end{tabular}

[1] $4 \mathrm{~J}$ Solar Simulator adjusted to 1sc-AM0

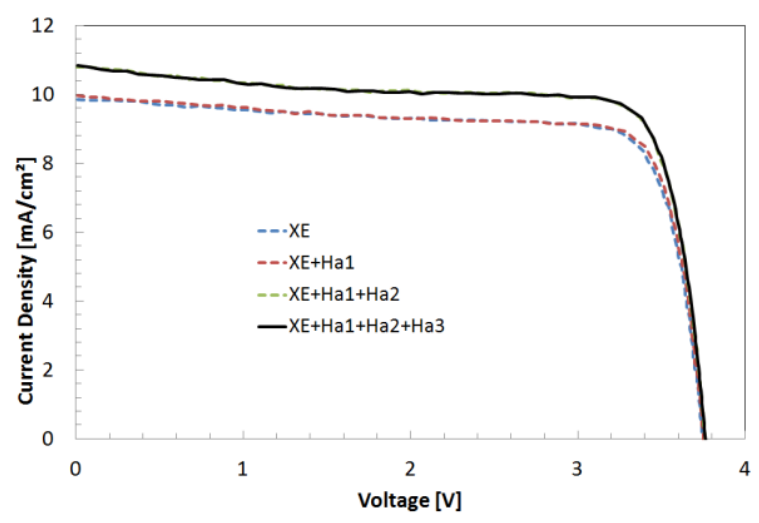

Figure 6. Current-voltage curves of $4 J$ solar cell during the $4 J$ solar simulator setting process.

Current-voltage curves of the $4 \mathrm{~J}$ solar cell measured during the $4 \mathrm{~J}$ solar simulator adjustment process are depicted in Fig. 6. These curves indicate that the InGaAs junction (J3) was the limited sub-cell under the Xe light source, because, when adding the second light source Ha1, no major impact in the I-V curve shape of the $4 \mathrm{~J}$ cell is noticed. Nevertheless, adding the third light source $\mathrm{Ha} 2$ to achieve eventually AM0 equivalent illumination conditions in this sub-cell gives rise to an increased short-circuit current of the $4 \mathrm{~J}$ solar cell. This 
is sustained as expected, when adding the fourth light source $\mathrm{Ha} 3$, since $\mathrm{Ha} 3$ only contributes to increase the irradiance level on the Ge sub-cell (J4). The limiting cell at AM0 illumination conditions as derived from the I-V curves of 4J SCRC set in Fig. 7 is AlInGaAs (J2). This has been also confirmed by further increasing the illumination level of $\mathrm{Ha} 2$ light source and noticing no relevant impact on the I-V curve shape.

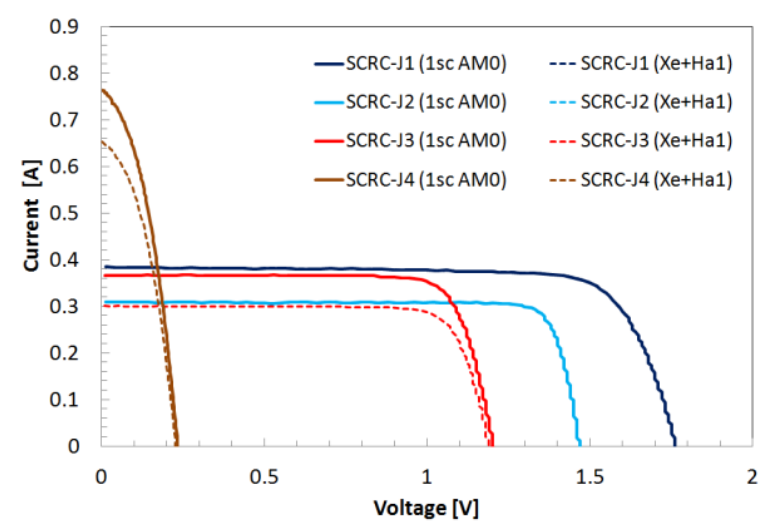

Figure 7. Current-voltage curves of 4J SCRC set during the $4 J$ solar simulator setting process.

\section{CONCLUSIONS}

In this work external quantum efficiency (EQE) results of a $4 \mathrm{~J}$ solar cell by CESI have been determined at INTA-Spasolab. The applied measurement method allows the EQE measurement system to be configured quickly, by changing optical bandpass filters, in order to switch from $3 \mathrm{~J}$ to $4 \mathrm{~J}$ solar cells. The EQE curves of higher bandgap junctions are reported including corrections of the parasitic EQE.

After adapting a solar simulator utilised so far for electric performance measurements on triple junction solar cells, first results of EP measurements of a $4 \mathrm{~J}$ solar cell at $25^{\circ} \mathrm{C}$ have been obtained. The results confirm that the modified CESI $4 \mathrm{~J}$ solar cell with the new proposed InGaAs structure [6] is not the limiting subcell under AM0 illumination conditions.

INTA-Spasolab future works are addressed to consolidate accurate effective irradiance adjustments. Spectrometric characterization as performed in [11] are planned to determine measurement uncertainty of electrical performance measurement at AM0 standard test conditions.

\section{REFERENCES}

1. Emery, K. et al. (2000). "Procedures for evaluating multi-junction concentrators". In Proc. 28th IEEE Photovoltaic Specialists Conference, pp1126-1130.

2. Gras, A. et al. (2002). “Analysis for multi-junction solar cell measurements at Spasolab". In Proc. 6th European Space Power Conference, ESA SP-502, pp577-580.

3. Meusel, M. et al. (2006). "Characterization of monolithic III-V multi-junction solar cellschallenges and application". Solar Energy Materials \& Solar Cells 90, pp3268-3275.

4. Gras, A. et al. (2008). "Multi-Source solar simulator characterization for establishing AM0 equivalent conditions", In Proc. 8th European Space Power Conference. ESA SP-661 (CDROM).

5. Campesato, R. et al. (2013). "Electron and proton irradiation on high efficiency III-V solar cells based on three and four junctions". In Proc. 28th European Photovoltaic Solar Energy Conference, pp531-535

6. Campesato, R., Gori, G., Casale \& M., Gabetta, G. (2014). "High Efficiency Four junction lattice matched solar cells for space applications: analysis of radiation hardness against $1 \mathrm{MeV}$ electrons". In Proc. 29th European Photovoltaic Solar Energy Conference, pp2031-2035.

7. Blanco Moriana, G., Fernández-Marín, J., Jüngst, G. \& Taylor, A. (2010). "Testing Methods to Quantify the Effects of Irradiation of Various Energies Protons and Electrons on the Performance of Triple Junction Solar Cells". In Proc. 25th European Photovoltaic Solar Energy Conference, pp872-876.

8. ECSS-E-ST-20-08C Rev. 1 (18 July 2012). "Space Engineering - Photovoltaic assemblies and components". ECSS Secretariat, ESA-ESTEC Requirements \& Standards Division, Noordwijk, The Netherlands.

9. Siefer, G., Baur, C. \& Bett, A. (2010). "External quantum efficiency measurements of germanium bottom sub-cells: measurement artefact and its solutions". In Proc. 35th IEEE Photovoltaic Specialists Conference, pp704-707.

10. Steiner et al. (2013). "Measuring IV Curves and Sub-cell Photocurrents in the Presence of Luminescent Coupling". IEEE J. Photovolt., vol. 3, no. 2, pp879-887.

11. Jüngst, G., Gras, A. \& Baur, C. (2013). "Measurement uncertainty for electric performance calibration of triple junction solar cells at Spasolab". In Proc. 28th European Photovoltaic Solar Energy Conference, pp540543. 